\title{
STUDY OF LINEAR ELECTRIC MOTOR MAGNETIC SYSTEM OF HAND-HELD ELECTRIFIED TOOL
}

\author{
Sergey Antonov \\ Stavropol State Agrarian University, Russia \\ antonov_serg@mail.ru
}

\begin{abstract}
In modern gardening, there are many technological processes that use hand tools. These processes account for about $40 \%$ of the labor costs in the process of gardening. In this regard, the cost of horticultural products increases, which affects their competitiveness in the market economy. The use of an electrified or mechanized tool will improve the production efficiency and reduce the cost of horticultural products. Currently, hydraulic and pneumatic drives are widely used. However, these drives have many disadvantages that lead to a decrease in the efficiency of the installations. Therefore, the electric drive is increasingly used. The existing electrified tool uses a DC motor as an electric drive. The most unreliable element of the motor is the brush mechanism. The use of a linear electric motor for the drive of the tool will increase its operational reliability and energy efficiency. This is possible due to the advantages of the linear electric drive, such as simplification of the mechanical part, increased speed and positioning accuracy of the electric motor armature. The proposed electric drive is characterized by low noise level and ease of maintenance. This stage in the development of a linear electric drive is characterized by a small range of tasks to be solved. The proposed design of a linear electric motor will allow, in general, to consolidate the possibility of its use in agricultural production, and in particular for a handheld electrified tool for caring for a garden. Modern design of electrical devices should use existing software systems for modeling magnetic systems. This will make it possible to more effectively solve the problem of increasing the efficiency of the magnetic system of the electric motor. To study the magnetic system of a linear electric motor, we use the ElCut program. The aim of the study is to optimize the magnetic system of the linear electric motor of a hand-held electrified tool. This will increase the force generated by the magnetic field acting on the armature. As a result of the research, the maximum value of the electromagnetic force reaches $53.7 \mathrm{~N}$. In the further design of the power tool, it is necessary to correctly select the kinematic diagram for its effective operation.
\end{abstract}

Keywords: lopper, electromagnet, electric motor, coil, flux, induction, gardening, pruning.

\section{Introduction}

Scientists from other countries are conducting research on the development of hand-held electrified tools, taking into account the processes of wood cutting [1-2]. Works [3-6] are devoted to general design issues of linear motors. In scientific articles [7-10], tubular linear electric motors of the synchronous type and permanent magnets are considered. Basically, research on linear electric drives is aimed at creating motors that drive vehicles, moving devices with parameters for accurate positioning in space [11-13]. For hand tools, the linear electric drive is not used in the world practice. Therefore, there is a need to develop linear motors for handheld electrified tools.

Most of the labor in industrial horticulture is spent on gardening processes. The most timeconsuming process is detailed pruning of tree branches. For these purposes, pruners, delimbers and hacksaws are used. For example, the Makita pruner (Fig. 1a), the Karsher delimber (Fig. 1b) and the Bosch hacksaw (Fig. 1c).
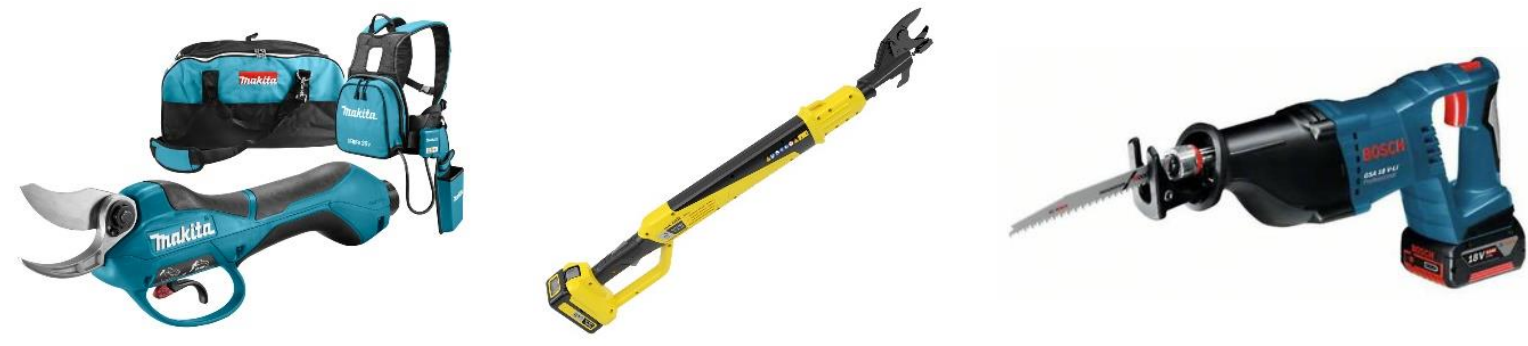

Fig. 1. Hand-held electrified tree pruning tool

This electrified tool uses a DC (direct current) motor as a drive for the working mechanism (cutting blades, hacksaw blade) (Fig. 2). 


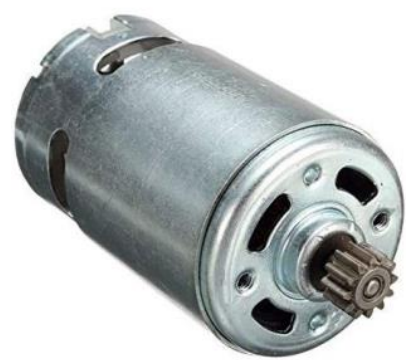

Fig. 2. DC electric motor

The brush mechanism of a DC motor reduces its operational reliability. The rotational motion of the motor armature must be converted into a reciprocating motion of the cutting blades or hacksaw blade. The operating principle of a linear electric motor is based on the reciprocating movement of the armature under the influence of an electromagnetic field created by magnetizing coils. The application area of linear motors is mainly vibration tools. For example, a jackhammer, a perforator, a device for driving metal rods into the ground, piston pumps and vibration machines of grain elevators [14; 15]. In this regard, a linear electric motor should be used for a hand-held electrified tool for the care of trees in gardens.

\section{Materials and methods}

The linear electric motor, proposed for use as a hand tool drive, consists of a first magnetizing pole (1), a second magnetizing pole (2) and non-magnetic inserts $(3,4,5)$ located in them. The magnetizing coil (7) is located on a non-magnetic frame (6). Inside the housing (8) with insulation (9), the first (10) and the second (12) covers fixed with screws $(11,13)$, a magnetizing coil $(7)$ is installed. The armature (14) of the linear electric motor consists of magnetic $(15,16,17,18)$ and non-magnetic $(19,20,21)$ sleeves. It is secured with sleeve bearings $(22,23)$. The spring (24) is needed to return the armature to its original position (Fig. 3).

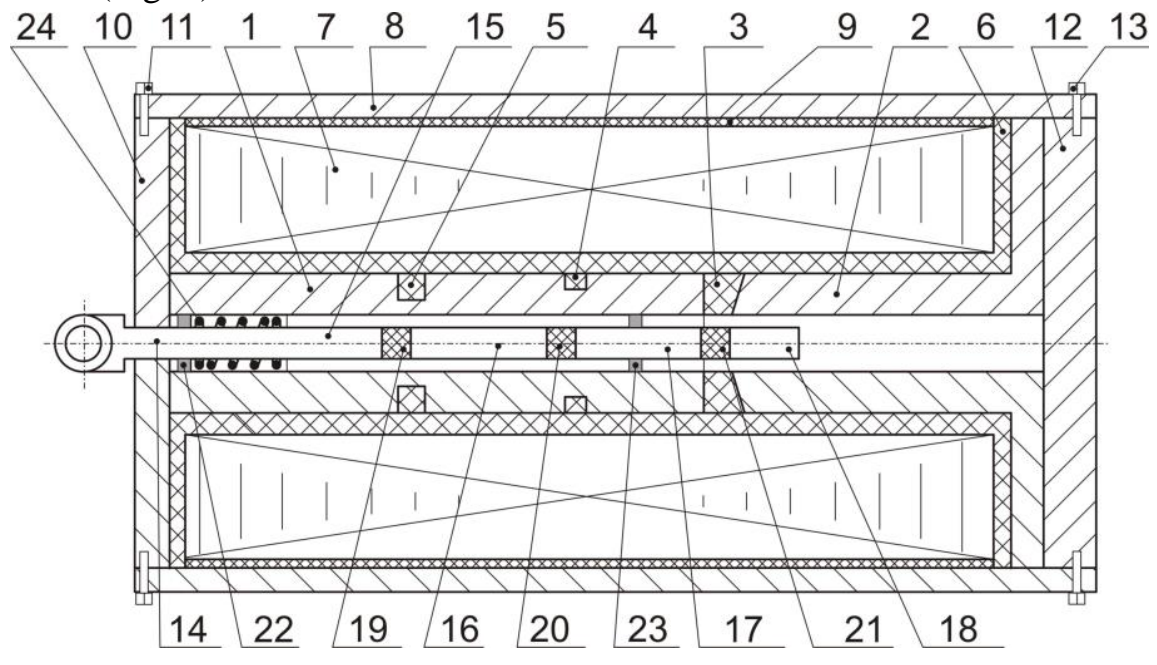

Fig. 3. Linear electric motor

The linear electric motor works as follows. With the magnetizing coil disconnected, the armature is in its original position under the influence of the spring. When DC voltage is applied to the magnetizing coil, the current begins to flow through it, which creates a magnetic flux $\Phi$. This magnetic flux closes along the housing, the first and second magnetizing poles, the armature and the first cover (Fig. 4).

The operating principle of the electric motor is to separate the magnetic flux $\Phi$ into magnetic fluxes $\Phi_{1}, \Phi_{1 \delta}, \Phi_{2}, \Phi_{2 \delta}, \Phi_{3}, \Phi_{3 \delta}$. This separation of flux occurs due to saturation of the magnetic system in places where non-magnetic inserts are present. The passage of fluxes $\Phi_{1}, \Phi_{2}, \Phi_{3}$ leads to the appearance of the electromagnetic force acting on the armature. When the voltage is disconnected from the magnetizing coil, the armature under the action of the spring moves to its original state [16-19]. 


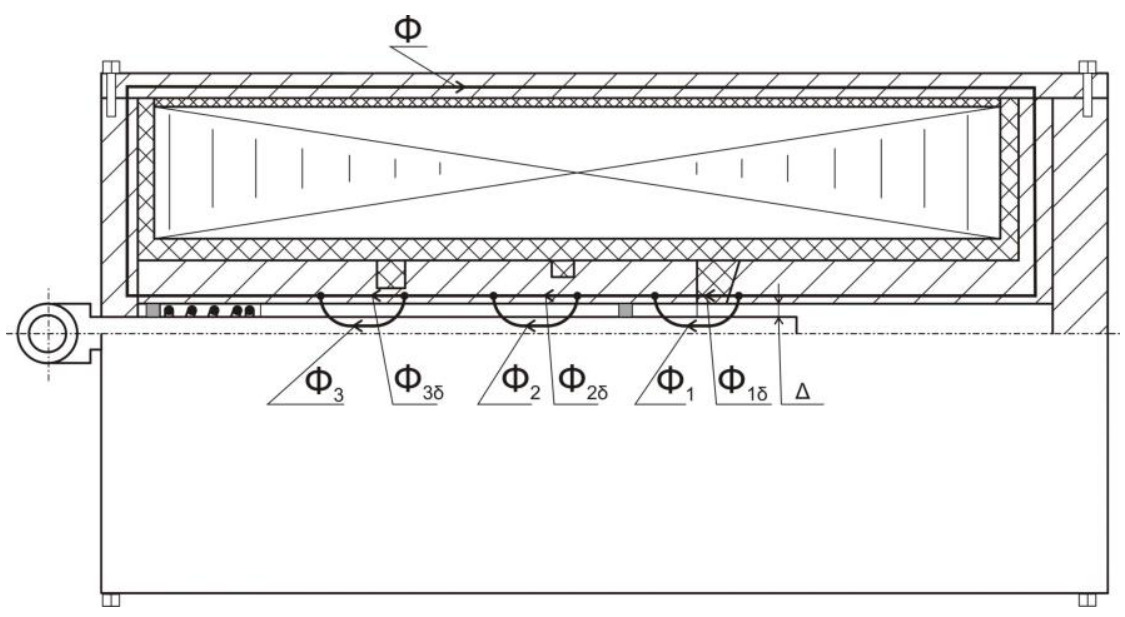

Fig. 4. Operating principle of a linear electric motor

The search for a rational design of the magnetic system of a linear electric motor is carried out in the ElCut software application. The program allows to calculate the value of the magnetic induction in a cylindrical coordinate system (1).

$$
B_{z}=\frac{1}{r} \frac{\partial(r A)}{\partial r}, B_{r}=-\frac{\partial A}{\partial z}
$$

To solve the problem, the Poisson's equation is used for the vector magnetic potential $A$. In this case, the magnetic induction is determined as $R=\operatorname{rot} A$. When solving our problem, the magnetic induction vector $B$ lies in the $z r$ plane (cylindrical coordinate system). Taking this, Poisson's (2) equation will have the form

$$
\frac{\partial}{\partial r}\left(\frac{1}{r \mu_{z}} \frac{\partial(r A)}{\partial r}+\frac{\partial}{\partial z}\left(\frac{1}{\mu_{r}} \frac{\partial A}{\partial z}\right)\right)=-j+\left(\frac{\partial H_{r}}{\partial z}-\frac{\partial H_{z}}{\partial r}\right)
$$

where $\mu_{z}, \mu_{r}$-magnetic permeability;

$H_{z}, H_{r}$ - coercitive force;

$j$ - current density.

For the operability of a linear electric motor, the presence of non-magnetic inserts and non-magnetic sleeves is important. Therefore, when determining the most rational design of the magnetic system of a linear electric motor, we single out two optimization factors. The first variation factor $(\alpha)$ is the bevel angle of non-magnetic sleeves $\left(15^{\circ}, 30^{\circ}, 45^{\circ}, 60^{\circ}, 75^{\circ}, 90^{\circ}\right)$. The second variation factor $(\beta)$ is the bevel angle of non-magnetic inserts $\left(15^{\circ}, 30^{\circ}, 45^{\circ}, 60^{\circ}, 75^{\circ}, 90^{\circ}\right)$ (Fig. 5).

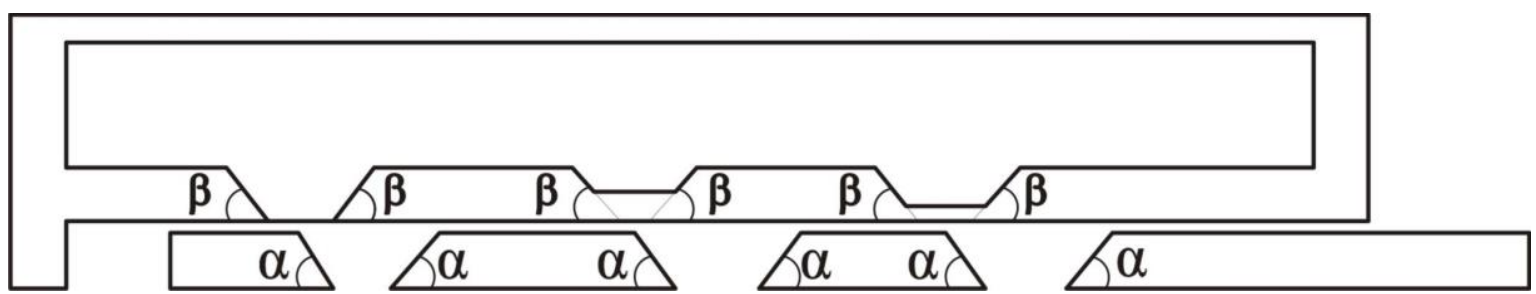

Fig. 5. Research parameters of the magnetic system of a linear electric motor

The ElCut software application allows to calculate the magnetic system using the finite element method with high accuracy. In this case, the initial correct formulation of the problem is important.

\section{Results and discussion}

The main parameters for solving the problem in the ElCut program are: building a geometric model, setting the properties of structural elements (coil, non-magnetic inserts, non-magnetic sleeves, magnetic system, magnetic sleeves), setting boundary conditions. To solve the problem, it is necessary to construct a mesh of finite elements (Fig. 6). 


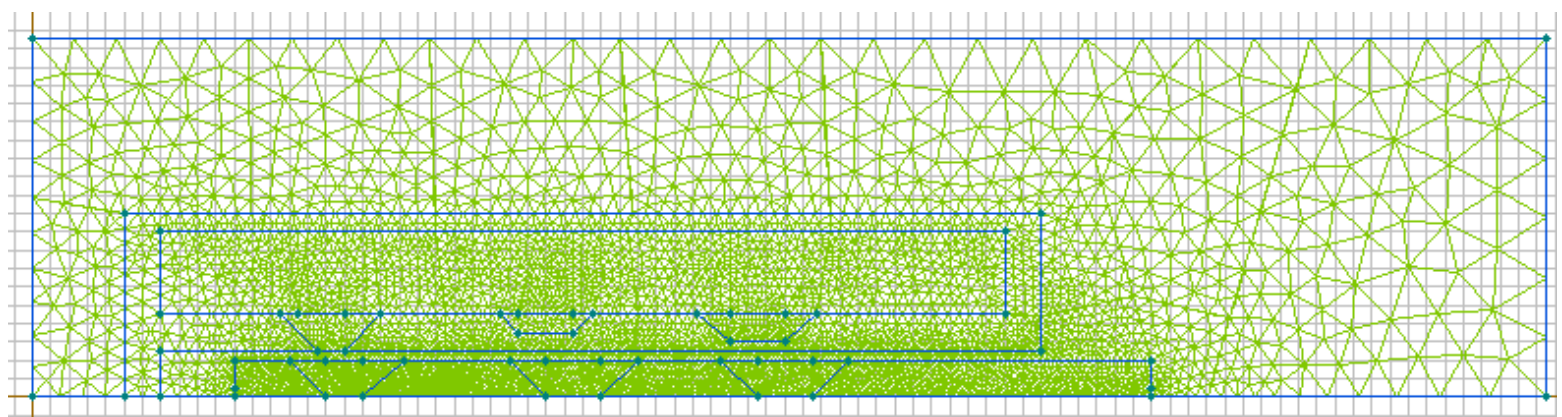

Fig. 6. Finite element meshing

Calculating the task, we get a picture of the magnetic fluxes distribution in the magnetic system of a linear electric motor (Fig. 7).

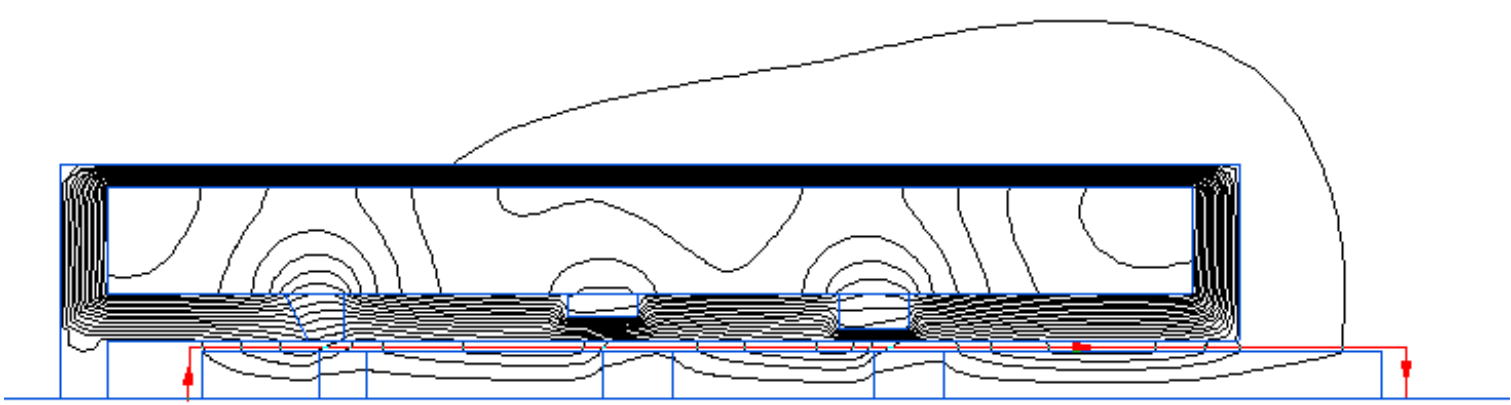

Fig. 7. Result of calculating the magnetic system of a linear electric motor

The main analyzed parameter of the operation of a linear electric motor is the generated electromagnetic force. It will be used in the further design of the device for hand-held electrified tools.

The results of the study of the magnetic system design features, taking into account certain parameters, are presented in Table 1.

Table 1

Electromagnetic force acting on the armature $(H)$

\begin{tabular}{|c|c|c|c|c|c|c|}
\hline \multirow{2}{*}{$\begin{array}{c}\text { Bevel angle of } \\
\text { non-magnetic } \\
\text { inserts } \boldsymbol{\beta} \mathbf{~}^{\mathbf{0}}\end{array}$} & $\mathbf{1 5}$ & $\mathbf{3 0}$ & $\mathbf{4 5}$ & $\mathbf{6 0}$ & $\mathbf{7 5}$ & $\mathbf{9 0}$ \\
\cline { 2 - 7 } & 12.7 & 13.1 & 13.9 & 16.9 & 22.4 & 27.6 \\
\hline 15 & 13.0 & 13.5 & 14.1 & 17.5 & 25.2 & 32.5 \\
\hline 30 & 13.6 & 13.9 & 14.3 & 21.3 & 29.1 & 37.7 \\
\hline 45 & 14.7 & 16.8 & 20.7 & 24.2 & 31.3 & 41.4 \\
\hline 60 & 22.8 & 24.6 & 28.5 & 30.8 & 32.7 & 47.5 \\
\hline 75 & 26.6 & 31.4 & 36.9 & 40.3 & 46.7 & 53.5 \\
\hline 90 &
\end{tabular}

Analyzing the obtained data, we can say that there is an increase in the generated electromagnetic force with an increase in the bevel angle of both non-magnetic sleeves and non-magnetic inserts.

For high-quality design of an effective tool, after determining the optimal, developed forces, it is necessary to calculate the kinematic diagram of the transfer of this force to the actuator.

\section{Conclusions}

1. Based on the results presented in the study, the following conclusions can be drawn. An increase in the bevel angle of non-magnetic sleeves from $15^{\circ}$ to $90^{\circ}$, leads to an increase in the electromagnetic force from $12.7 \mathrm{~N}$ to $27.6 \mathrm{~N}$.

2. An increase in the bevel angle of non-magnetic inserts from $15^{\circ}$ to $90^{\circ}$, leads to an increase in the electromagnetic force from $12.7 \mathrm{~N}$ to $26.6 \mathrm{~N}$.

3. At the same time, a simultaneous increase in the angles contributes to an increase in the electromagnetic force up to $53.7 \mathrm{~N}$. 


\section{References}

[1] Hedrick U.P. Cyclopedia of Hardy Fruits. New York: The MacMillan Company, 1922. 370 pp.

[2] Csanády E., Magoss E. Mechanics of Wood Machining. 2-nd ed. Springer-Verlag Berlin Heidelberg, 2013. 199 p.

[3] Wang J., Jewell G.W., Howe D. A general framework for the analysis and design of tubular linear PM machines, IEEE Trans., MAG-35(2), 1999, pp. 1986-2000.

[4] Chapman S. Electric Machinery Fundamentals. 5th Edition. - USA: McGraw-Hill Science, 2005. $708 \mathrm{p}$.

[5] Duy V.H., Dao T.T., Zelinka I., Kim S.B., Phuong T.T. (eds.) AETA 2017 - Recent Advances in Electrical Engineering and Related Sciences: Theory and Application. Springer, 2018. $1086 \mathrm{p}$.

[6] Wang J., Howe D. Tubular modular PM machines equipped with quasi-Halbach magnetized magnets - Part I + II, IEEE Trans., MAG-41(9), 2005, pp. 2470-2489.

[7] Krop D.C.J., Lomonova E.A., Vandenput A.J.A., Application of Schwarz-Cristoffel mapping to PM linear motor analysis, IEEE Trans., MAG-44(3), 2008, pp. 352-359.

[8] Zhu Y.-W., Cho Y.-H. Thrust ripple suppression of PM linear synchronous motor, IEEE Trans., MAG-43(6), 2007, pp. 2537-2539.

[9] Zheng P., Chen A., Thelin P., Arshad W.M., Sadarangani Ch. Research on a tubular longitudinal flux PM linear generator used for free-piston energy converter, IEEE Trans., MAG-43(1), 2007, pp. 447-449.

[10] Prudell J., Stoddard M., Amon E., Brekken T.K.A., von Jouanne A. A PM tubular linear generator for ocean wave energy conversion, IEEE Trans., IA-46(6), 2010, pp. 2392-2400.

[11] Niu S., Ho S.L., Fu W.N. Performance analysis of a novel magnetic-geared tubular linear PM machine, IEEE Trans., MAG-47(10), 2011, pp. 3598-3601.

[12] Holehous R.C., Atallah K., Wang J. Design and realization of a linear magnetic gear, IEEE Trans., MAG-47(10), 2011, pp. 4171-4174.

[13] Wang J., Atalah K., Wang W. Analysis of a magnetic screw for high force density linear electromagnetic actuators, IEEE Trans., MAG-47(10), 2011, pp. 4477-4480.

[14] Тавасиев Р.М. Средства малой механизации для плодовых насаждений крестьянских (Фермерских) хозяйств (Means of small-scale mechanization for fruit plantations of peasant (farmer) farms): diss. ... doct. tech. sciences. Vladikavkaz, 2009. 277 p. (In Russian)

[15] Туриев О.И. Разработка и обоснование основных параметров обрезчика ветвей для крестьянских (Фермерских) хозяйств (Development and justification of the main parameters of the cutter branches for peasant (farm) farms): diss. ... cand. tech. sciences. Vladikavkaz, 1999. 162 p. (In Russian)

[16] Antonov S., Nikitenko G., Grinchenko V., Molchanov A., Avdeeva V. Electromechanical secateurs based on a linear electric motor and determination of the cutting force of branches of fruit trees. Engineering for rural development, Jelgava Latvia, 2018, pp. 514-518.

[17] Antonov S., Nikitenko G., Linear electric motor for handheld electrified tools used in gardening. Engineering for rural development, Jelgava Latvia, 2019, pp. 804-807.

[18] Antonov S., Nikitenko G., Simulation of linear electric motor for electromechanical pruner. Proceeding of 7th International Conference on "Trends in Agricultural Engineering 2019", 2019. Prague, Czech Republic, 2019, pp. 40-44.

[19] Antonov S., Nikitenko G. Lopper for trimming trees driven by linear electric. Engineering for rural development, Jelgava Latvia, 2020. pp. 833-837. 